\title{
TINGKAT KEPUASAN MAHASISWA TERHADAP KINERJA PELAYANAN AKADEMIK SEKOLAH TINGGI ILMU EKONOMI NASIONAL INDONESIA (STIENI) JAKARTA
}

\author{
Gary Yefta Herbeth Siagian \\ Program Studi Manajemen Sekolah Tinggi Ilmu Ekonomi Nasional Indonesia (STIENI) Jakarta \\ Email : gary.siagian@yahoo.co.id
}

DOI: http://dx.doi.org/10.35908/jeg.v5i1.951

\begin{abstract}
This research is aimed at finding out about the characteristics and level of the students' satisfaction with the academic service performance at the Indonesian National School of Economics (Sekolah Tinggi Ilmu Ekonomi Nasional Indonesia (STIENI]), Jakarta. This research has applied the methods of surveying and of quata sampling to 100 respondents. The analytical data has used descriptive analysis, the Method of Important Performance Analysis (MIPA), and the Customer Satisfaction Index (CSI). The results hereof indicate the respondents' characteristics that the majority, 70\%, of the STIENI students are female. As to their age, the majority, 80\%, are > 25 years. The semester/ grade in this research is the third (3rd), being 40\% in number. The study program, 70\%, is management. Concerning the students'status, 75\% of them are employees' class. As to the frequency of visits, the majority of STIENI students are $>3$ times or $70 \%$ relative to lecturing needs. The students' level of satisfaction with the academic service performance provided by the STIENI campus is 0.60 based on the criterion of being content. It means that the academic service performance of STIENI campus has lived up to the students' expectations.
\end{abstract}

Keyword : Satisfaction level, Servis Performance, Academic, Students

\begin{abstract}
ABSTRAK
Tujuan dari penelitian ini adalah untuk mengetahui karakteristik dan tingkat kepuasan mahasiswa terhadap kinerja pelayanan akademik di Sekolah Tinggi Ilmu Ekonomi Nasional Indonesia (STIENI) Jakarta. Penelitian ini menggunakan metode survei. Metode pengambilan sampel secara quata sampling sebanyak 100 responden. Data analisis menggunakan analisis deskriptif, Metode Important Performance Analisis (MIPA), dan Customer Satisfaction Index (CSI). Hasil penelitian menunjukkan karakteristik responden bahwa mayoritas mahasiswa/i STIENI yaitu perempuan sebesar 70\%. Untuk usia mahasiswa/i STIENI mayoritas yaitu usia $>25$ tahun sebesar $80 \%$, untuk semester/tingkatan dalam penelitian ini yaitu tingkat tiga (3) yaitu sebesar $40 \%$. Untuk program studi (prodi) sebesar $70 \%$ yaitu manajemen. Untuk status mahasiswa/i yaitu sebesar $75 \%$ kelas karyawan. Untuk frekuensi berkunjung, mahasiswa/i STIENI mayoritas sebesar $>3$ kali sebesar $70 \%$ dengan keperluan perkuliahan. Sedangkan untuk tingkat kepuasan mahasiswa terhadap kinerja pelayanan akademik kampus STIENI yaitu 0,60 dengan kriteria cukup puas. Artinya kinerja pelayanan akademik kampus STIENI sudah sesuai dengan harapan mahasiswa.
\end{abstract}

\section{Kata Kunci : Tingkat Kepuasan, Kinerja Pelayanan, Akademik, Mahasiswa}

\section{PENDAHULUAN}

Kualitas merupakan salah satu strategi managing servis quality yang paling penting dalam sebuah organisasi jasa. Ada 5 (lima) faktor untuk melihat kualitas sebuah pelayanan yaitu: 1 . Kehandalan (realibilitas). Realibilitas merupakan kemampuan memberikan layanan yang dijanjikan dengan akurat dan terpercaya semenjak saat pertama. 2. Jaminan, mencakup pengetahuan, kemampuan dan perilaku karyawan untuk menerapkan kepercayaan dan keyakinan kepada pelanggan. 3. Bukti fisik/wujud, berupa fasilitas fisik, peralatan yang diperlukan sebagai bentuk dari representasi jasa yang diberikan oleh perusahaan. 4 . Empati, empati merupakan perhatian individu karyawan dari perusahaan tersebut kepada pelanggannya. 5. Daya tanggap, daya tanggap merupakan kesiapan para karyawan untuk memberikan pelayanan jasa yang dibutuhkan oleh pelanggan (Parasuraman et al, (1985). Menurut 
Yuliastuti, (2000) ada 3 (tiga) hal dalam sebuah organisasi jasa yaitu : managing differentiation, managing productivity, dan managing servis quality.

Kampus merupakan tempat dimana kumpulan mahasiswa/i menimba ilmu, Sekolah Tinggi Ilmu Ekonomi Nasional Indonesia (STIENI) merupakan salah satu institusi pendidikan di Jakarta. STIENI memiliki 2 (dua) program studi yaitu akuntansi dan manajemen untuk kelas regular maupun karyawan. Kampus ini berdiri sejak tahun 1986.

Tabel 1. Jumlah Mahasiswa STIENI Program Studi Akuntansi dan Manajemen Tahun 20122017

\begin{tabular}{|c|c|c|c|c|}
\hline \multirow{2}{*}{ Tahun } & \multicolumn{4}{|c|}{ Program Studi } \\
\cline { 2 - 5 } & $\begin{array}{c}\text { Akun } \\
\text { tansi } \\
\text { (Regu } \\
\text { ler) }\end{array}$ & $\begin{array}{c}\text { Akun } \\
\text { tansi } \\
\text { (Karya } \\
\text { wan) }\end{array}$ & $\begin{array}{c}\text { Mana } \\
\text { jemen } \\
\text { (Regu } \\
\text { ler) }\end{array}$ & $\begin{array}{c}\text { Mana } \\
\text { jemen } \\
\text { (Karya } \\
\text { wan) }\end{array}$ \\
\hline 2012 & $\begin{array}{c}120 \\
\text { orang }\end{array}$ & $\begin{array}{c}213 \\
\text { orang }\end{array}$ & $\begin{array}{c}150 \\
\text { orang }\end{array}$ & $\begin{array}{c}265 \\
\text { orang }\end{array}$ \\
\hline 2013 & $\begin{array}{c}132 \\
\text { orang }\end{array}$ & $\begin{array}{c}200 \\
\text { orang }\end{array}$ & $\begin{array}{c}175 \\
\text { orang }\end{array}$ & $\begin{array}{c}200 \\
\text { orang }\end{array}$ \\
\hline 2014 & $\begin{array}{c}100 \\
\text { orang }\end{array}$ & $\begin{array}{c}150 \\
\text { orang }\end{array}$ & $\begin{array}{c}150 \\
\text { orang }\end{array}$ & $\begin{array}{c}160 \\
\text { orang }\end{array}$ \\
\hline 2015 & 75 & 80 & 100 & 154 \\
& orang & orang & orang & orang \\
\hline 2016 & 70 & 80 & 70 & 99 \\
& orang & orang & orang & orang \\
\hline 2017 & $\begin{array}{c}80 \\
\text { orang }\end{array}$ & $\begin{array}{c}100 \\
\text { orang }\end{array}$ & $\begin{array}{c}85 \\
\text { orang }\end{array}$ & $\begin{array}{c}100 \\
\text { orang }\end{array}$ \\
\hline
\end{tabular}

Sumber : Data Diolah, (2019).

Berdasarkan Tabel diatas menjelaskan bahwa jumlah mahasiswa/i STIENI mengalami penurunan secara signifikan dari tahun ke tahun sebesar $50 \%$ dari jumlah mahasiswa/i dari Tahun 2012 hingga Tahun 2017 sebesar 153 orang. Hal ini dikarena kinerja pelayanan publik belum secara optimal. Menurut Rangkuti, (2013) mengatakan bahwa perusahaan harus berorientasi pada kepentingan pelanggan dengan memperhatikan komponen kualitas pelanggan. Pelanggan akan merasa puas apabila harapan yang mereka inginkan dapat dipenuhi oleh Kampus STIENI.

Kinerja atau Performance adalah hasil kerja yang dapat dicapai oleh seseorang atau sekelompok orang dalam suatu organisasi, sesuai dengan wewenang dan tanggungjawab masing-masing dalam rangka upaya mencapai tujuan organisasi bersangkutan secara legal, tidak melanggar hukum dan sesuai dengan moral maupun etika
(Prawirosentono, 2008). Pelayanan merupakan suatu aktivitas atau serangkaian aktivitas yang bersifat tidak kasat mata (tidak dapat diraba) yang terjadi sebagai akibat adanya interaksi antara konsumen dan karyawan atau hal-hal yang lain yang disediakan oleh perusahaan pemberi pelayanan untuk memecahkan permasalahan konsumen/pelanggan (Ratminto dan Winarsih, 2006).

Kepuasan merupakan perasaan senang atau kecewa seseorang yang berasal dari perbandingan persepsi atau kesan terhadap kinerja (hasil) suatu produk dan harapan-harapannya (Kotler, 1997). Kepuasan pelanggan merupakan suatu tingkatan dimana perkiraan kinerja produk sesuai dengan harapan pembeli (Kotler dan Amstrong, 2001). Kepuasan pelanggan tercapai apabila kinerja (performace) lebih besar harapan (expectation) dan pelanggan tidak merasa puas apabila harapan lebih besar dari kinerja (Tjiptono, 2004). Kepuasan pelanggan bergantung pada perkiraan kinerja produk atau jasa dalam memberikan nilai relatif pembeli. Tujuan penelitian ini adalah untuk mengetahui karakteristik dan tingkat kepuasan mahasiswa terhadap kinerja pelayanan akademik di Sekolah Tinggi Ilmu Ekonomi Nasional Indonesia (STIENI) Jakarta.

\section{METODE PENELITIAN}

Penelitian dilaksanakan pada bulan Januari-Maret 2019. Penelitian dilakukan pada Sekolah Tinggi Ilmu Ekonomi Nasional Indonesia (STIENI) Jalan Matraman Raya Nomor 3-5 Jakarta Timur yang dilakukan secara sengaja (purposive), mengingat STIENI merupakan merupakan kampus yang memiliki luas bangunan yang minim seperti pertokoan di daerah Matraman Jakarta Timur yang berdiri sejak 33 Tahun. Sampel penelitian ini adalah mahasiswa STIENI. Metode pengambilan sampel ditentukan dengan quata sampling, yaitu teknik untuk menentukan sampel dari populasi yang mempunyai ciri-ciri tertentu sampai jumlah (kuota) yang diinginkan (Sugiyono, 2009). Jumlah responden diambil sebanyak 100 responden.

Metode pengumpulan data melalui wawancara langsung dengan mahasiswa STIENI yang berpedoman pada kuesioner. Data-data yang diperoleh berupa data primer dan sekunder. Data primer diperoleh dari hasil 
observasi dan wawancara langsung dengan mahasiswa STIENI dan seluruh jajaran tinggi dan karyawan kampus STIENI. Data sekunder diperoleh dari jurnal-jurnal dan karya ilmiah yang mendukung dalam penelitian.

\section{Metode Analisis Data}

Sebuah menguji instrumen dikatakan baik apabila dilakukan 2 (dua) cara yaitu menguji sah (valid) dan dapat dipercaya (reliable). Pengujian ini dilakukan dengan 100 responden yang tersebar. Uji validitas merupakan uji instrumen data untuk mengetahui seberapa cermat suatu item dalam mengukur apa yang ingin diukur. Item dikatakan valid jika adanya korelasi yang signifikan dengan skor totalnya, hal ini menunjukkan adanya dukungan item tersebut dalam mengungkap suatu yang ingin diungkapkan. Dengan rumus kolerasi product moment (kolerasi person) : $\mathrm{r}_{\mathrm{xy}}=$ $\frac{n(\Sigma X Y)-(\Sigma X)(\Sigma Y)}{\left.\sqrt{\{n \Sigma} X^{2}-(\Sigma X)^{2}\right\}\left\{n Y^{2}-(\Sigma Y)^{2}\right\}}$. Dimana $r_{x y}=$ koefisien korelasi antara $\mathrm{X}$ dengan $\mathrm{Y}, \mathrm{n}=$ jumlah sampel, $\sum X Y=$ jumlah total data $X Y, \sum X=$ jumlah total data variabel $\mathrm{X}, \sum \mathrm{Y}=$ jumlah total data variabel Y (Riadi, 2016). Pengujian dilakukan dengan kriteria menggunakan $\mathrm{r}$ tabel pada tingkat signifikansi 0,05 dengan uji 2 sisi. Jika nilai positif dan $r$ hitung $\geq r$ tabel maka item dapat dinyatakan valid, jika $r$ hitung $<\mathrm{r}$ tabel maka item dinyatakan tidak valid. Uji reliabilitas digunakan untuk mengetahui keajengan atau konsistensi alat ukur yang biasanya digunakan kuesioner. Metode yang sering digunakan dalam penelitian untuk mengukur rentangan dengan skala likert yaitu cronbach alpha. Dengan rumus : $\alpha=\frac{\mathrm{k}}{\mathrm{k}-1} \mathrm{X}$ $\left(1-\frac{\sum \mathrm{S}_{\mathrm{i}}^{2}}{\mathrm{~s}_{\mathrm{t}}^{2}}\right)$, dimana $\alpha=$ koefisien reliabilitas, $\mathrm{k}=$ banyaknya butir yang valid, $\mathrm{s}_{\mathrm{t}}^{2}=$ varians skor total, $\mathrm{s}_{\mathrm{t}}^{2}=$ varians skor butir. Untuk menentukan apakah instrumen reliable atau tidak menggunakan batasan 0,6. Menurut Sekaran (1992), mengatakan reliabilitas kurang dari 0,6 adalah kurang baik, sedangkan 0,7 dapat diterima, dan $>0,8$ adalah baik.
Untuk mengetahui karakteristik responden digunakan analisis deskriptif. Analisis deskriptif merupakan analisis statistik yang digunakan untuk menganalisis data dengan cara mendeskriptifkan atau menggambarkan data yang telah terkumpul sebagaimana adanya tanpa maksud membuat kesimpulan yang berlaku untuk umum atau generalisasi (Sugiyono, 2007). Analisis deskriptif hanya berhubungan dengan hal menguraikan atau memberikan keteranganketerangan mengenai suatu data atau keadaan (Priyatno, 2014). Variabel analisis deskriptif dalam penelitian ini yaitu : jenis kelamin usia, tingkatan/ semester, program studi dan frekuensi berkunjung.

Kepuasan mahasiswa/i terhadap kinerja pelayanan akademik kampus STIENI ditentukan pada dimensi kualitas jasa dalam variabel atribut yang diukur, yaitu : (1) realibilty, merupakan kemampuan untuk memberikan pelayanan yang sesuai dengan janji yang ditawarkan, (2) responsiveness, merupakan respon atau kesigapan karyawan dalam membantu pelanggan dan memberikan pelayanan yang cepat dan tanggap yang meliputi kesigapan karyawan dalam melayani pelanggan, kecepatan karyawan dalam menangani transaksi, dan penanganan keluhan pelanggan. (3) assurance, merupakan kemampuan karyawan atas pengetahuan produk secara tepat, kualitas kerahmah-tamahan, perhatian dan kesopanan dalam memberikan pelayanan, keterampilan dalam memberikan informasi, kemampuan dalam memberikan keamanan dalam memanfaatkan jasa yang ditawarkan, dan kemampuan dalam menanamkan kepercayaan pelanggan terhadap perusahaan. (4) emphaty, adalah perhatian secara individual yang diberikan perusahaan kepada pelanggan, seperti kemudahan untuk menghubungi perusahaan, kemampuan karyawan untuk berkomunikasi dengan pelanggan, dan usaha perusahaan untuk memahami kebutuhan dan keinginan pelanggan (5) tangibles, meliputi penampilan fisik seperti gedung dan ruangan front office, tersedianya tempat parkir, kebersihan, kerapihan, dan kenyamanan ruangan, kelengkapan perlengkapan komunikasi dan penampilan karyawan (Umar, 2003). Tingkat dirasakan (perceived) dan 
harapan (expectation) diukur dengan dengan menggunakan skala likert dengan skor 1 apabila mahasiswa menilai suatu atribut kinerja pelayanan akademik sangat tidak sesuai dan sangat tidak puas, skor 2 apabila mahasiswa menilai suatu atribut kinerja pelayanan akademik tidak sesuai dan tidak puas. Skor 3 apabila mahasiswa menilai suatu atribut kinerja pelayanan akademik cukup sesuai dan cukup puas. skor 4 apabila mahasiswa menilai suatu atribut kinerja pelayanan akademik sesuai dan puas. Dan skor 5 apabila mahasiswa menilai suatu atribut kinerja pelayanan akademik sangat sesuai dan sangat puas.

Untuk mengukur tingkat kepuasan mahasiswa dalam menilai kinerja pelayanan akademik di Sekolah Tinggi Ilmu Ekonomi Nasional Indonesia (STIENI) menggunakan Metode Important Performance Analysis (IPA) dan Customer Satisfaction Index (CSI) (Dickson et al, 2004). Dengan Rumus: TKI = $\frac{X i}{Y i} \mathrm{x} 100 \%$. Dimana TKI $=$ Tingkat Kesesuaian Index, $\mathrm{Xi}=$ skor penilaian tingkat kinerja perusahaan, $\mathrm{Yi}=$ skor penilaian kepentingan perusahaan (Simamora, 2004). Tingkat Kesesuaian Index (TKI) dapat mengartikan sejauh mana karakteristik atribut memenuhi standar-standar yang telah ditetapkan oleh mahasiswa sesuai dengan dirasakan dan harapan. Sedangkan untuk mengukur skor rata-rata variabel tingkat dirasakan (perceived) dan tingkat harapan (expectation) mahasiswa secara keseluruhan, digunakan rumus yaitu : $X$ $=\frac{\sum_{\mathrm{i}}^{\mathrm{n}}=1 \mathrm{x}}{\mathrm{k}}$ dan $\mathrm{Y}=\frac{\sum_{\mathrm{i}}^{\mathrm{n}}=1 \mathrm{Y}}{\mathrm{k}}$, dimana sumbu mendatar (X) akan mengisi oleh skor tingkat kinerja kampus, sedangkan sumbu tegak (Y) akan mengisi skor tingkat kepentingan mahasiswa. Penyederhanaan rumus yaitu : $\mathrm{X}=\frac{\sum \mathrm{X}}{\mathrm{n}}$ dan $\mathrm{Y}=\frac{\Sigma Y}{n}$, dimana $\mathrm{n}=$ jumlah responden. Setelah diperoleh $\mathrm{X}$ dan $\mathrm{Y}$ maka langkah selanjutnya membuat diagram kartesius. Diagram kartesius merupakan suatu bangun yang terbagi atas 4 (empat) bagian yang dibatasi oleh dua buah garis yang berpotongan tegak lurus pada titik $\mathrm{X}$ dan $\mathrm{Y}$ (Simamora, 2004). Strategi yang dapat dilakukan berdasarkan posisi masing-masing atribut pada ke-4 (empat) kuadran adalah :
1. Kuadran I (Prioritas Utama) menggambarkan atribut-atribut dianggap sangat penting oleh mahasiswa tetapi pihak kampus belum melaksanakan sesuai dengan keinginan mahasiswa, sehingga mahasiswa merasa tidak puas $(\mathrm{Y}<\mathrm{X})$.

2. Kuadran II (Pertahankan Prestasi) menunjukkan atribut-atribut yang dianggap penting oleh mahasiswa dan telah dilaksanakan dengan baik oleh pihak kampus sehingga mahasiswa merasa puas, oleh karena itu pihak kampus harus mempertahankan kinerja atribut-atribut tersebut $(\mathrm{Y}=\mathrm{X})$.

3. Kuadran III (Prioritas Rendah) merupakan wilayah yang memuat faktor-faktor yang dianggap kurang penting oleh mahasiswa dan pada kenyataannya kepuasan yang dirasa konsumen tidak terlalu istimewa atau biasa saja $(Y \neq X)$.

4. Kuadran IV (Berlebihan) menunjukkan atribut-atribut yang dianggap kurang penting oleh konsumen tetapi pihak kampus telah menjalankan dengan sangat baik atau memuaskan, sehingga mahasiswa menilai kinerja kampus terlalu berlebihan $(\mathrm{Y}>\mathrm{X})$.

Index kepuasan konsumen (Customer Satisfaction Index/CSI) ditentukan dengan rumus yang terdiri dari dari 4 (empat) langkah yaitu : (1). Menentukan Mean Satisfaction Score (MSS) dan Mean Importance Score (MIS) pada setiap variabel. (2). Menghitung Weight Factors (WF), dengan rumus : WF $=\frac{\mathrm{MIS}}{\sum \mathrm{MIS}}$, (3). Menghitung Weight Score (WS), dengan rumus WS = WFX MSS, (4). Menentukan CSI, dengan rumus CSI $=\frac{\mathrm{wS}}{\mathrm{n}}$.

Hasil perhitungan dari Customer Satisfaction Index (CSI) dimasukkan kedalam kategori skala kepuasan konsumen. Skala kepuasan mahasiswa. Skala kepuasan mahasiswa yang umum dipakai untuk menginterpretasikan index dapat dilihat pada Tabel 2.

Tabel 2. Kriteria Customer Satisfaction Index (CSI)

\begin{tabular}{cc}
\hline Nilai Index & $\begin{array}{c}\text { Kriteria Customer } \\
\text { Satisfaction Index }(\mathrm{CSI})\end{array}$ \\
\hline $0,81-1,00$ & Sangat Puas \\
$0,66-0,80$ & Puas \\
$0,51-0,65$ & Cukup Puas
\end{tabular}




\begin{tabular}{cc}
$0,35-0,50$ & Kurang Puas \\
$0,00-0.34$ & Tidak Puas \\
\hline
\end{tabular}

Sumber : Wildan (2005).

\section{HASIL DAN PEMBAHASAN}

Keadaan Umum Responden

Berdasarkan hasil penelitian, menunjukkan bahwa mayoritas mahasiswa/i STIENI yaitu perempuan sebesar $70 \%$, sisanya sebesar $30 \%$ adalah laki-laki. Untuk usia mahasiswa/i STIENI mayoritas yaitu usia > 25 tahun sebesar $80 \%$, sisanya sebesar $20 \%$ yaitu mahasiswa/i berusia $<25$ tahun. Untuk semester/tingkatan dalam penelitian ini yaitu tingkat tiga (3) yaitu sebesar $40 \%$, tingkat satu (1) yaitu sebesar $20 \%$, tingkat lima (5) yaitu sebesar $30 \%$ dan untuk tingkat tujuh (7) sebesar 5\% dan sisanya sebesar 5\% untuk tingkat $>7$. Untuk program studi (prodi) sebesar $70 \%$ yaitu manajemen dan sisanya $30 \%$ yaitu akuntansi. Untuk status mahasiswa/i yaitu sebesar $75 \%$ kelas karyawan dan sisanya $25 \%$ untuk kelas regular. Untuk frekuensi berkunjung, mahasiswa/i STIENI mayoritas sebesar >3 kali sebesar $70 \%$ dengan keperluan perkuliahan, sisanya sebesar $30 \%$ dengan keperluan administrasi dan berkunjung.

\section{Hasil Tingkat Kepuasan Mahasiswa terhadap Kinerja Pelayanan Akademik STIENI}

Kepuasan merupakan kemampuan layanan atau produk untuk memenuhi kebutuhan pelanggan (Smith, Heindel, and Torres-Ayala, 2008). Menurut Susanto, (2014) menyatakan kepuasan merupakan evaluasi yang menggambarkan seseorang atas perasaan sikap senang atau tidak senang dalam beraktivitas. Kepuasan mahasiswa merupakan evaluasi emosional berbagai hasil dan pengalaman yang berhubungan dengan pendidikan yang benar-benar mereka peroleh dibandingkan dengan harapan mereka sebelumnya (Sumaedi, 2011). Berdasarkan hasil tersebut, diperoleh kinerja pelayanan akademik yang dirasakan mahasiswa kampus STIENI (X) dan tingkat yang diharapkan mahasiswa terhadap pelayanan kampus STIENI (Y) yang dijadikan garis pembagi dalam diagram kartesius Important Performance Analysis (IPA). Berdasarkan Tabel 3, hasil rata-rata layanan kinerja pelayanan akademik yang dirasakan mahasiswa/i STIENI adalah kemampuan dalam emberikan keamanan yaitu dengan nilai 3,85. Sedangkan untuk atribut yang memiliki nilai rata-rata paling rendah dari hasil penilaian rata-rata layanan kinerja pelayanan akademik yang dirasakan mahasiswa kampus STIENI adalah Kesesuaian janji yang disampaikan dengan nilai rata-rata tingkat kinerja 2,12 .

Tabel 3. Hasil Rata-Rata Layanan Kinerja Pelayanan Akademik yang Dirasakan dan Harapan Mahasiswa STIENI

\begin{tabular}{clcc}
\hline No. & Layanan (Atribut) & $\begin{array}{c}\text { Rata- } \\
\text { Rata (X) }\end{array}$ & $\begin{array}{c}\text { Rata- } \\
\text { rata (Y) }\end{array}$ \\
\hline $\begin{array}{c}\text { Responsiveness (ketanggapan) } \\
\text { 1. }\end{array}$ & $\begin{array}{l}\text { Ketepatan waktu } \\
\text { layanan akademik }\end{array}$ & 2,91 & 3,38 \\
2. $\quad \begin{array}{l}\text { Kesesuaian janji yang } \\
\text { disampaikan }\end{array}$ & 2,12 & 2,92 \\
3. $\quad \begin{array}{l}\text { Profesionalisme } \\
\text { akademik }\end{array}$ & 3,10 & 4,34 \\
4. $\begin{array}{l}\text { Kesigapan pelayanan } \\
\text { akademik }\end{array}$ & 3,06 & 3,38 \\
\hline
\end{tabular}

Reliability (keandalan)

1. Kecepatan dalam 3,36 3,36 transaksi

2. Penanganan keluhan $\quad 3,04 \quad 2,94$

3. Pengetahuan produk 3,21 3,50 layanan

Emphaty (empati)

1. Kualitas keramahan $2,93 \quad 3,4$

2. Perhatian dan 3,30 3,16 kesopanan

3. Keterampilan dalam $3,07 \quad 3,08$ memberikan informasi

4. Kemampuan dalam $3,85 \quad 3,41$ memberikan keamanan

Assurance (jaminan)

1. Kemampuan dalam 2,51 3,00 menanamkan kepercayaan

2. Kemudahan dalam 3,32 3,02 menghubungi

3. Kemampuan dalam 3,17 2,98 berkomunikasi

4. Usaha untuk 3,09 3,20 memenuhi kebutuhan

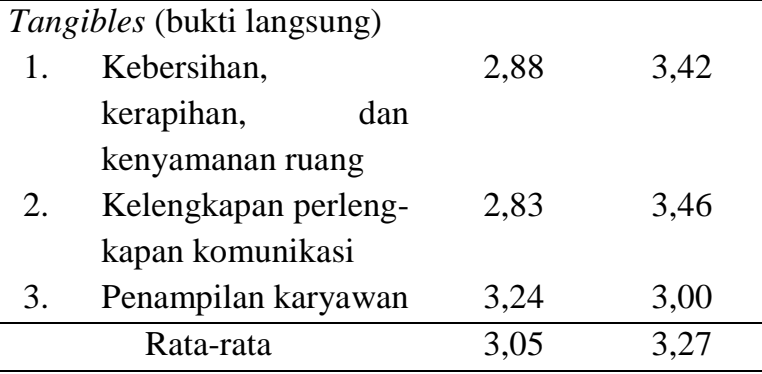

Sumber : Data Primer, 2019 (Diolah) 
Berdasarkan Tabel 3 dapat terlihat layanan atribut kualitas jasa pelayanan akademik yang dianggap paling diharapkan oleh mahasiswa kampus STIENI, yaitu profesionalisme akademik sebesar 4.34. Sedangkan untuk atribut yang memiliki nilai rata-rata paling rendah adalah kesesuaian janji yang diharapkan dengan nilai sebesar 2,92.

Berdasarkan Tingkat Kesesuaian Index (TKI) dapat dilihat pada kuadran I (prioritas utama) yaitu atribut ketepatan waktu layanan akademik, profesionalisme akademik, kesigapan pelayanan akademik, pengetahuan produk layanan, kualitas keramahan, keterampilan dalam memberikan informasi, kemampuan dalam menanamkan kepercayaan, usaha untuk memenuhi kebutuhan, kebersihan, kerapihan, dan kenyamanan ruang dan kelengkapan perlengkapan komunikasi. Pada kuadran ini merupakan atribut yang dianggap penting oleh mahasiswa/i STIENI namun pelaksanaannya kurang baik oleh pelayanan kampus STIENI sehingga perlu adanya perbaikan kinerja pada Kampus tersebut. Pada kuadran I ini merupakan strategi pemasaran yang dinilai sangat penting namun pelaksanaannya belum memenuhi harapan mahasiswa/i, walaupun mahasiswa/i merasa sangat puas.

Pada kuadaran II (pertahankan prestasi) yaitu untuk atribut kecepatan dalam transaksi. Pada kuadran ini merupakan atribut yang dianggap penting oleh mahasiswa/i STIENI dalam pelaksanaannya telah sesuai dengan harapan oleh mahasiswa/i kampus STIENI. Pada kuadran III (prioritas rendah) yaitu tidak ada. Pada kuadran ini menunjukkan bahwa tingkat dirasakan dan diharapkan oleh mahasiswa/i STIENI kurang penting dan pelaksanaannya dinilai cukup. Pada kuadran IV (kuadran berlebihan) yaitu untuk atribut kesesuaian janji yang disampaikan, penanganan keluhan, perhatian dan kesopanan, kemampuan dalam memberikan keamanan, kemudahan dalam menghubungi, kemampuan dalam berkomunikasi dan penampilan karyawan. Pada kuadran ini menunjukkan strategi pemaasaran kampus STIENI yang kurang penting bagi mahasiswa/i kampus tersebut, namun dalam pelaksanaannya dinilai sudah baik oleh mahasiswa/i menilai tidak ada pemasaran yang dianggap kurang penting bagi mahasiswa/i dan pelaksanaannya sangat baik.

Tabel 4. Hasil Perhitungan Kepuasan Mahasiswa STIENI terhadap Kinerja Pelayanan Akademik

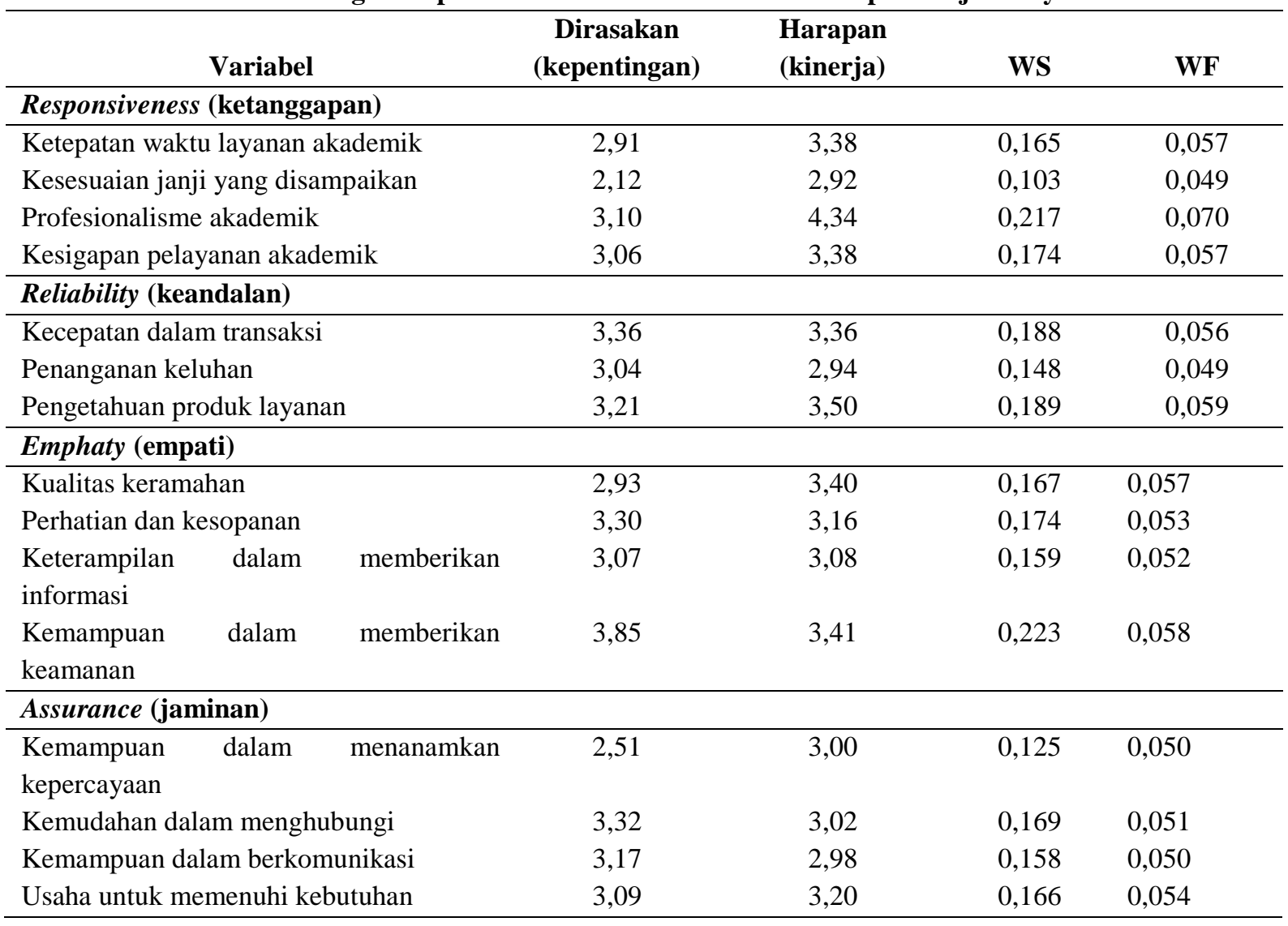




\begin{tabular}{llccc}
\hline Tangibles (bukti langsung) & & & & \\
\hline Kebersihan, kerapihan, dan kenyamanan & 2,88 & 3,42 & 0,167 & 0,058 \\
ruang & & & & \\
Kelengkapan perlengkapan komunikasi & 2,83 & 3,46 & 0,166 & 0,059 \\
Penampilan karyawan & 3,24 & 3,00 & 0,162 & 0,050 \\
\hline Avarage & 3,05 & 3,27 & & \\
\hline Sum & 54,99 & 58,95 & 3,02 & \\
\hline & CSI $=\mathbf{0 , 6 0}$ & & & \\
\hline
\end{tabular}

Sumber : Data Primer, 2019 (Diolah)

Berdasarkan Tabel 4, hasil akhir perhitungan Metode Customer Satisfaction Index (CSI) terhadap 5 (lima) variabel atribut kinerja pelayanan akademik karyawan kampus STIENI dalam 18 item variabel kriteria adalah 0,60. Hal ini menunjukkan tingkat kepuasan mahasiswa STIENI terhadap 5 (lima) variabel atribut kinerja pelayanan di kampus STIENI yaitu cukup puas. Hal ini dapat diartikan bahwa pada umumnya mahasiswa STIENI untuk prodi Akuntansi dan Manajemen merasa yakin dan percaya akan kemampuan kinerja pelayanan di kampus STIENI dalam melayani mahasiswa dengan baik. Kepuasan adalah perasaan senang dan kecewa seseorang yang muncul setelah membandingkan antara kinerja (hasil) yang dipikirkan terhadap kinerja (hasil) yang diharapkan. Kepuasan mahasiswa mempengaruhi minat untuk kembali ke kampus yang sama. Mahasiswa yang puas akan menjadi pelanggan yang loyal, seperti melakukan promosi mulut ke mulut bagi calon mahasiswa lainnya, yang diharapkan sangat positif untuk kampus STIENI. Kepuasan merupakan pengalaman konsumen yang akan mengendap di dalam ingatan konsumen, dan mempengaruhi proses pengambilan keputusan pembelian ulang bagi produk yang sama (Hayaza, 2013).

\section{SIMPULAN}

Berdasarkan hasil penelitian dapat disimpulkan yaitu :

1. Bahwa mayoritas mahasiswa/i STIENI yaitu perempuan sebesar $70 \%$, sisanya sebesar $30 \%$ adalah laki-laki. Untuk usia mahasiswa/i STIENI mayoritas yaitu usia > 25 tahun sebesar $80 \%$, sisanya sebesar $20 \%$ yaitu mahasiswa/i berusia $<25$ tahun. Untuk semester/tingkatan dalam penelitian ini yaitu tingkat tiga (3) yaitu sebesar $40 \%$, tingkat satu (1) yaitu sebesar 20\%, tingkat lima (5) yaitu sebesar 30\% dan untuk tingkat tujuh (7) sebesar 5\% dan sisanya sebesar 5\% untuk tingkat $>7$. Untuk program studi (prodi) sebesar $70 \%$ yaitu manajemen dan sisanya $30 \%$ yaitu akuntansi. Untuk status mahasiswa/i yaitu sebesar $75 \%$ kelas karyawan dan sisanya $25 \%$ untuk kelas regular. Untuk frekuensi berkunjung, mahasiswa/i STIENI mayoritas sebesar >3 kali sebesar 70\% dengan keperluan perkuliahan, sisanya sebesar $30 \%$ dengan keperluan administrasi dan berkunjung.

2. Hasil akhir perhitungan Metode Customer Satisfaction Index (CSI) terhadap 5 (lima) variabel atribut kinerja pelayanan akademik karyawan kampus STIENI dalam 18 item variabel kriteria adalah 0,60 yaitu cukup puas, namun untuk mencapai kinerja pelayanan akademik pelayanan yang optimal diperlukan perbaikan mengenai memperbaiki sarana dan prasana di wilayah kampus seperti kotak saran.

\section{DAFTAR PUSTAKA}

Dickson, D., C. Saunders,. O. Hargie. 1994. Social Skils in Interpersonal Communication, Ed.3. London.

Hayaza, Y, T, 2013. Analisis Kepuasan Pasien Terhadap Kualitas Pelayanan Kamar Obat di Puskesmas Surabaya Utara, Fakultas Farmasi. Universitas Surabaya. Surabaya. Calyptra : Vol.2 No.2.

Kotler, P. 1997. Manajemen Pemasaran Analisis. Implementasi dan Kontrol Jilid 1. Prenhallindo. Jakarta.

Kotler, P,. dan G. Amstrong. 2001. Prinsip-Prinsip Pemasaran (Jilid 1, Edisi 8). Erlangga. Jakarta.

Martasubrata, N, dan Sumano. 2016. Mutu Layanan Akademik Sebagai Deteminan Kepuasan Mahasiswa. Jurnal Pendidikan Manajemen Perkantoran. Universitas Pendidikan Indonesia. Vol. 1 No. $1 \mathrm{Hal}$ 136-163. 
Parasuraman, V. A, Zeithaml, and L. L. Berry. 1985. A Conceptual Model Of Service Quality and For Future Research. Journal of Marketing. Vol. 49.

Priyatno, D. 2014. Pengolah Data Terpraktis SPSS 22. Andi. Yogyakarta.

Prawirosentono, S. 2008. Kebijakan Kinerja Karyawan, BPFE Yogyakarta, Yogyakarta. ISBN: 979-503-365-4

Rangkuti, F. 2013. Customer Servis Satisfaction \& Call Center Berdasarkan ISO 9001. Jakarta: PT. Gramedia Pustaka Utama.

Ratminto dan Winarsih S, Atik. 2006. Manajemen Pelayanan: Pengembangan Model Konseptual. Penerapan Citizen's dan Standar Pelayanan Minimal. Yogyakarta: Penerbit Pustaka Pelajar.

Riadi, E. 2016. Statistika Penelitian (Analisis Manual dan IBM SPSS). CV. Andi. Yogyakarta.

Sekaran, U. 1992. Research Methods For Business, A Skill Building Approach, $2^{\text {nd }}$ edition. John Wiley n Sons. New York.

Siagian, G, Y, H, Roessali W, dan Agustini, T, W. 2016. Sikap Konsumen Terhadap Keputusan Pembelian Bandeng Duri Lunak Di Toko Bandeng Juwana Kota Semarang. Tesis. Fakultas Peternakan dan Pertanian. Universitas Diponegoro. Semarang.

Sianipar, William Antartika dan Hadi Wahyono, 2018. Kinerja Pelayanan Publik PDAM Kabupaten Mempawah Berdasarkan Kepuasan Pelanggan. Jurnal Pembangunan Wilayah dan Kota.
Universitas Diponegoro Semarang. Vol. 14 No. 3.2130-224.

Simamora, B. 2004. Panduan Riset Perilaku Konsumen. PT. Gramedia Pustaka Utama. Jakarta.

Smith, G. G., Heindel, A. J., and Torres-Ayala, A. T. (2008). E-learning commodity or community: Disiplinary diferences between online courses. The Internet and Higher Education, 11(3), 152-159.

Sugiyono, 2007. Metode Penelitian Bisnis. CV. Alfabeta. Bandung. 2009. Statistika Penelitian. CV. Alfabeta. Bandung.

Sumaedi, S. 2011. The Effect of Student Perceived Service Quality and Perceived Price on Student Satisfaction. Management Science and Engineering, 5(1), 88-97.

Susanto, H. 2014. Pengaruh Layanan Akademik terhadap Kepuasan Mahasiswa. Jurnal Pendidikan Terbuka dan Jarak Jauh, 15(2), 88-98.

Tjiptono, F. 2004. Manajemen Jasa. Andi. Yogyakarta.

Umar, H. 2003. Metode Riset: Perilaku Konsumen Jasa. Ghalia Indonesia. Jakarta.

Wildan, 2005. Panduan Survey Kepuasan PT. Sucofindo. PT. Sucofindo. Jakarta.

Yuliastuti, R. 2000. Strategi Pemasaran Organisasi Jasa : Pencapaian Kepuasan Pelanggan Melalui Kualitas Pelayanan Jasa. Jurnal Kebi-Stiekers. Hal 13-78. 